\title{
Sleep parameters in rhesus monkeys by using actigraphy
}

\author{
Tomoyuki Kawada
}

Received: 21 May 2013 / Accepted: 28 May 2013 /Published online: 10 June 2013

(C) Springer-Verlag Berlin Heidelberg 2013

\section{Dear Editor;}

Andersen et al. (2013) reported the effect of methamphetamine on sleep parameters in rhesus monkeys by using actigraphy, named Actiwatch ${ }^{\circledR}$. They quoted some references (Mann et al. 2005; Andersen et al. 2010; Andersen et al. 2012) to establish the validity of their study. Sleep efficiency, sleep latency, and sleep fragmentation were selected as sleep parameters, which were calculated by using Actiware software program. As a conclusion, methamphetamine $(0.03 \mathrm{mg} / \mathrm{kg})$ disrupted sleep by producing an increase in sleep latency and sleep fragmentation, in combination with a decrease in sleep efficiency. After concluding the drug experiment, the effect disappeared.

I have two concerns on their study. First, actigraphy cannot become a substitute for sleep polysomnography. Actigraphy is based on an accelerometer for movement, and it does not directly reflect brain activity. They quoted one validation study with Actiwatch ${ }^{\circledR}$ (Terrill et al. 2010), but Terrill et al. mentioned that the sensitivity of detecting wakefulness during time in bed was poor. There is a cutoff value of Actiwatch ${ }^{\circledR}$ sensitivity for arriving at sleep/wake differentiation, which is initially set at 40 counts per minute. This value was originally determined for human subjects, and the cutoff value should be set according to each test situation.

Second, they prepared two concentrations of methamphetamine and the effect of methamphetamine treatment was evaluated. As an additional analysis, they calculated correlation coefficients between the intake of methamphetamine and three sleep parameters. Although statistical significance was observed in each relationship, the explanation rates were 0.27 or smaller. As the authors mentioned, further studies are needed to confirm the relationship.

I agree with the simplicity of actigraphy to monitor sleep, but much more trials are needed to establish validation for the application of actigraphy to small nonhuman primates. Activity monitoring and sleep monitoring are different concepts, and special caution should be paid when inferring sleep based on actigraphy (Terrill et al. 2010).

Conflict of interest None declared.

\section{References}

Andersen ML, Kessler E, Murnane KS, McClung JC, Tufik S, Howell LL (2010) Dopamine transporter-related effects of modafinil in rhesus monkeys. Psychopharmacology (Berl) 210:439-448

Andersen ML, Sawyer EK, Carroll FI, Howell LL (2012) Influence of chronic dopamine transporter inhibition by RTI-336 on motor behavior, sleep, and hormone levels in rhesus monkeys. Exp Clin Psychopharmacol 20:77-83

Andersen ML, Diaz MP, Murnane KS, Howell LL (2013) Effects of methamphetamine self-administration on actigraphy-based sleep parameters in rhesus monkeys. Psychopharmacology (Berl) 227:101-107

Mann TM, Williams KE, Pearce PC, Scott EA (2005) A novel method for activity monitoring in small non-human primates. Lab Anim 39:169-177

Terrill PI, Mason DG, Wilson SJ (2010) Development of a continuous multisite accelerometry system for studying movements during sleep. Conf Proc IEEE Eng Med Biol Soc 2010:6150-6153
T. Kawada $(\bowtie)$

Department of Hygiene and Public Health, Nippon Medical

School, 1-1-5 Sendagi, Bunkyo-Ku, Tokyo 113-8602, Japan

e-mail: kawada@nms.ac.jp 